\title{
(Scanning) Transmission Electron Microscope Study on the Misfit Layer Compounds $\left(\mathrm{NbSe}_{2}\right)_{4}(\mathrm{PbSe})_{4}$
}

\author{
Sujing Xie*, Ngoc T. Nguyen, David C. Johnson \\ *CAMCOR, University of Oregon, Eugene, Oregon 97403 \\ Department of Chemistry, University of Oregon, Eugene, Oregon 97403
}

The thermal conductivity depends on heat carried by phonons or lattice vibrations and electrical carriers. The previous studies indicate that much lower thermal conductivity can be obtained by introducing nanostructures such as synthesizing superlattices, quantum dots, nanocrystalline inclusions and selfassembled structure [1,2]. The misfit layered compounds are a structurally interesting subgroup of layered materials, consisting of interpenetrating transition metal dichalcogenide and distorted rock salt crystal structures with matching crystal parameters in the $\mathrm{b}$ and $\mathrm{c}$ dimensions, but an incommensurate or "mismatched" a lattice parameter [3,4]. The structural incoherent between components in the misfit layer compounds provides opportunities to interleave many potential constituents to tailor thermal conductivity [5]. In this study, the misfit layered compounds - $\left(\mathrm{NbSe}_{2}\right)_{4}(\mathrm{PbSe})_{4}$ nanolaminates, with five different stacking sequence $\left(\mathrm{NbSe}_{2}\right)_{4}(\mathrm{PbSe})_{4}(44),\left(\mathrm{NbSe}_{2}\right)_{3}(\mathrm{PbSe})_{3}\left(\mathrm{NbSe}_{2}\right)_{1}(\mathrm{PbSe})_{1}(33-11)$, $\left(\mathrm{NbSe}_{2}\right)_{3}(\mathrm{PbSe})_{2}\left(\mathrm{NbSe}_{2}\right)_{1}(\mathrm{PbSe})_{2}(32-12),\left(\mathrm{NbSe}_{2}\right)_{2}(\mathrm{PbSe})_{3}\left(\mathrm{NbSe}_{2}\right)_{2}(\mathrm{PbSe})_{1}(23-21)$ and $\left(\mathrm{NbSe}_{2}\right)_{2}(\mathrm{PbSe})_{2}\left(\mathrm{NbSe}_{2}\right)_{1}(\mathrm{PbSe})_{1}\left(\mathrm{NbSe}_{2}\right)_{1}(\mathrm{PbSe})_{1}(22-11-11)$, have been synthesized on Si substrate by the modulated elemental reactants method. A FEI Helios 600 dual-beam system was utilized to prepare cross-section TEM samples. FEI Titan 80-300 TEM was operated at $300 \mathrm{kV}$ to perform the high-angle annular dark-field scanning transmission electron microscopy (HAADF STEM) imaging and highresolution TEM imaging. High-resolution STEM investigations reveal that the unit cell contains four layers of $\mathrm{NdSe}_{2}$ and four layers of PbSe with the five different stacking sequences have been obtained. Examples of two stacking sequences: 33-11 and 22-11-11, are shown in Fig. 1 (a) and (b), respectively. The composite modulated structure consists of the periodical intergrowth of a pseudotetragonal $\mathrm{PbSe}$ layer and a pseudohexagonal layer $\mathrm{NbSe}_{2}$ with their planes perpendicular to the c-axis, as shown in Fig. 2. Crystallographic ordering and defects in the $\mathrm{NdSe}_{2}$ layer and $\mathrm{PbSe}$ layer were characterized by highresolution TEM images and electron diffraction. The effect of stacking sequence on the thermal conductivity of $\left(\mathrm{NbSe}_{2}\right)_{4}(\mathrm{PbSe})_{4}$ nanolaminates will also be explored.

References:

[1] R. Venkatasubramanian, R.E. Siivola, T. Colpitts, B.Oquinn, Nature 413 (2001), 597.

[2] T. Ikeda, L.A., Collins, V.A. Ravi, F.S. Gascoin, S.M. Haile, G.J. Snyder, J. Chem. Mater. 19 (2007), 763.

[3] A. Meerschaut, Curr. Opin. Solid State M 1(1996), 250.

[4] C. Heideman, N. Nguyen, J. Hanni, Q. Lin, S. Duncombe, D.C. Johnson, P. Zschack, J. Solid Sate Chem. 181 (2008), 1701. 

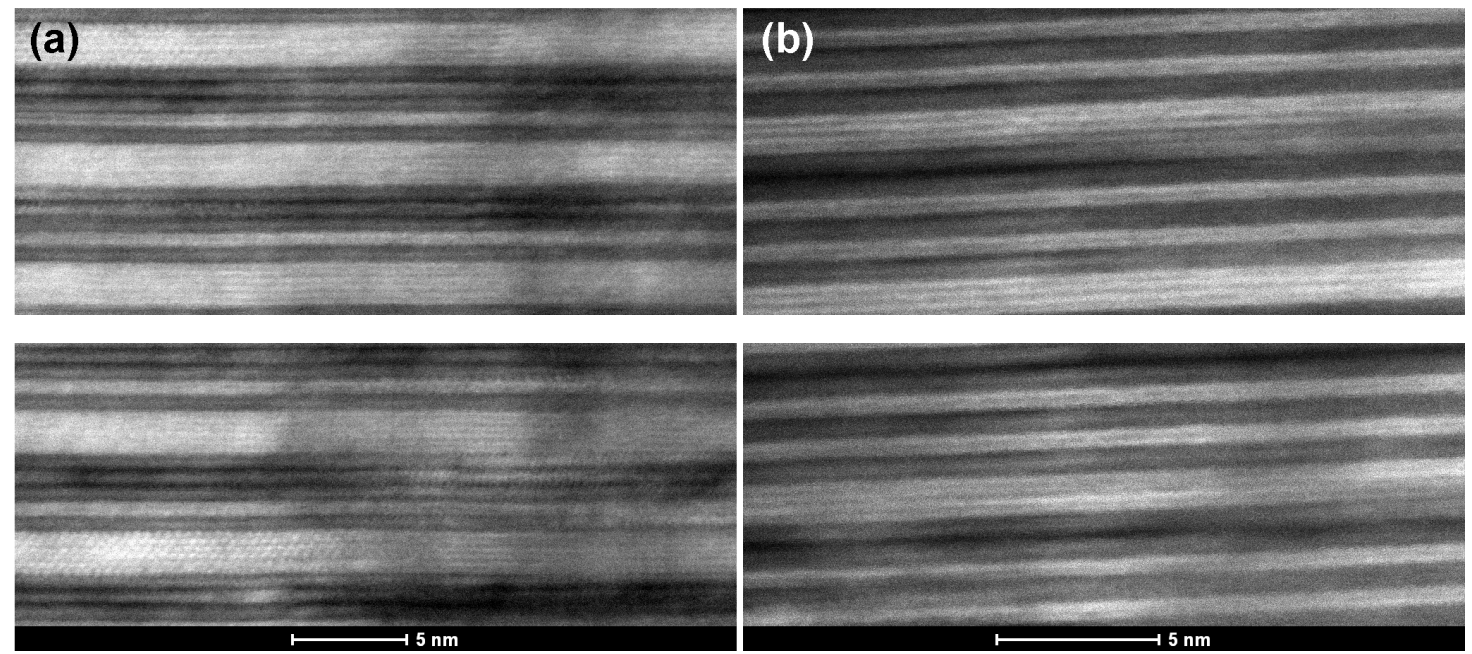

Fig. 1 High-angle annular dark field STEM image of misfit layer compound with a stacking sequence of (a) $\left(\mathrm{NbSe}_{2}\right)_{3}(\mathrm{PbSe})_{3}\left(\mathrm{NbSe}_{2}\right)_{1}(\mathrm{PbSe})_{1}$ and (b) $\left(\mathrm{NbSe}_{2}\right)_{2}(\mathrm{PbSe})_{2}\left(\mathrm{NbSe}_{2}\right)_{1}(\mathrm{PbSe})_{1}\left(\mathrm{NbSe}_{2}\right)_{1}(\mathrm{PbSe})_{1}$. In these images, the brighter lines are $\mathrm{PbSe}$ layer, and the darker lines are $\mathrm{NbSe}_{2}$ layer.
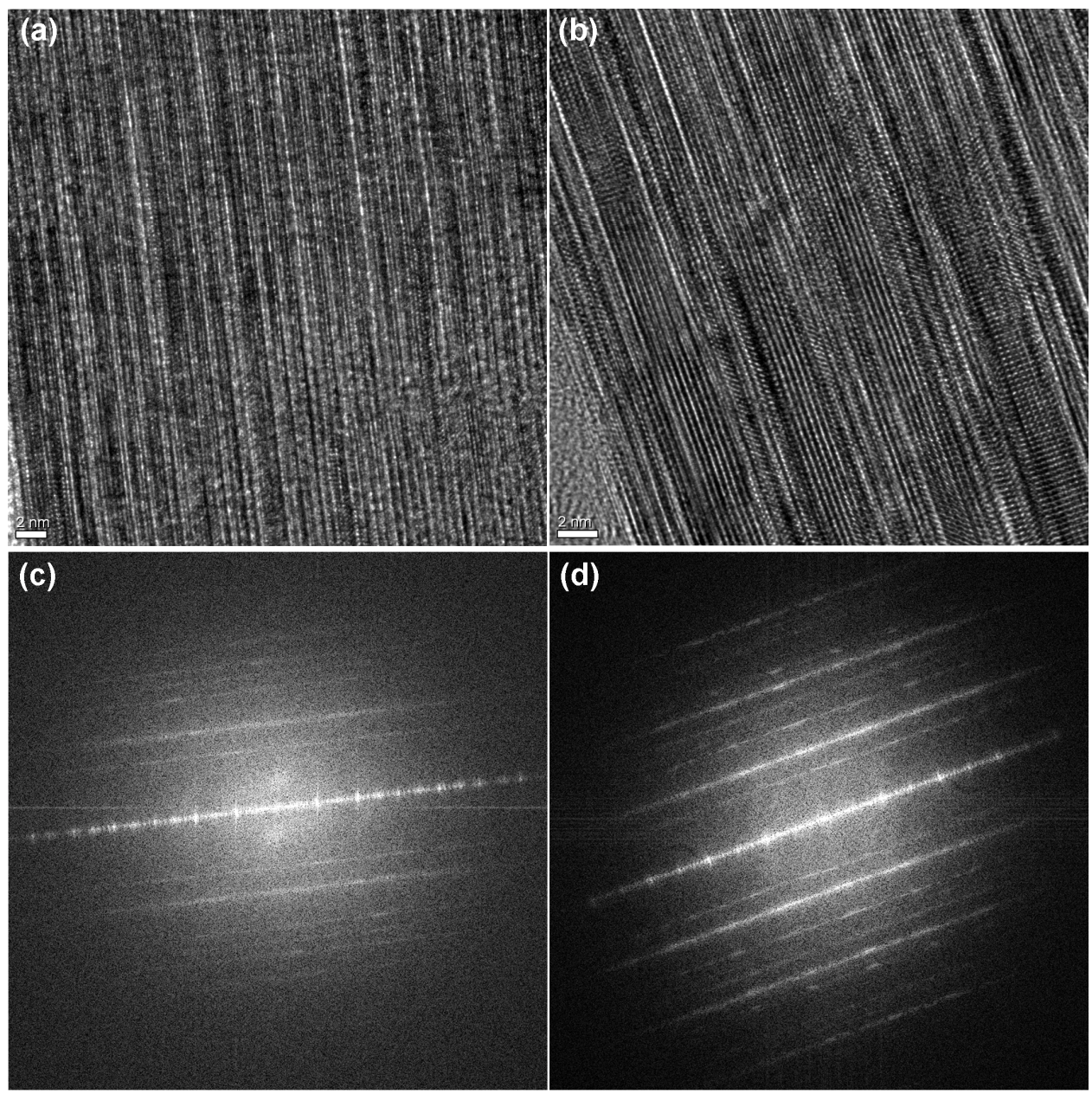

Fig. 2(a) High-resolution TEM image of $\left(\mathrm{NbSe}_{2}\right)_{3}(\mathrm{PbSe})_{3}\left(\mathrm{NbSe}_{2}\right)_{1}(\mathrm{PbSe})_{1}$; (b) highresolution TEM image of $\left(\mathrm{NbSe}_{2}\right)_{2}(\mathrm{PbSe})_{2}\left(\mathrm{NbSe}_{2}\right)_{1}(\mathrm{PbSe})_{1}\left(\mathrm{NbSe}_{2}\right)_{1}(\mathrm{PbSe})_{1}$; (c) Fast fourier transformation (FFT) of image (a); and (d) FFT of image (b). (c) and (d) reveal that the planes of PbSe and $\mathrm{NdSe} 2$ layers are perpendicular to the c-axis. 